\title{
Bladder Preservation for Muscle Invasive Bladder Cancer
}

\author{
Arafat Mirza $^{\mathrm{a}, *}$ and Ananya Choudhury ${ }^{\mathrm{a}, \mathrm{b}}$ \\ ${ }^{\text {a }}$ The Christie NHS Foundation Trust, Manchester, UK \\ ${ }^{\mathrm{b}}$ The Institute of Cancer Sciences, University of Manchester, Manchester Academic Health Sciences Centre, \\ Manchester, UK
}

\begin{abstract}
The standard treatment for muscle invasive bladder cancer (MIBC) has been considered to be radical cystectomy (RC) with pelvic lymphadenectomy. However morbidity and impact on quality of life is significant. Radiotherapy has been used in MIBC patients who choose bladder preservation or who are unfit for RC with comparable outcomes. Evidence from some prospective and large retrospective series supports the use of radiotherapy as an attractive alternative option. In this paper we review the evidence and practice of bladder preservation strategies with radiotherapy for muscle invasive bladder cancer.
\end{abstract}

Keywords: Bladder cancer, chemoradiotherapy, radical cystectomy, organ preservation

\section{BACKGROUND}

Over 10,000 patients are diagnosed with bladder cancer each year in the United Kingdom [1]. The incidence is 17 per 100,000 of the population with a male to female ratio of 5:2. Approximately one third of patients have stage II or IIII muscle invasive bladder (MIBC) cancer. The majority (80-90\%) of those diagnosed with MIBC are primary presentations while $10-20 \%$ of patients having had a previous history of mainly high risk superficial bladder cancer. Up until recently, the standard definitive treatment for MIBC has been considered to be radical cystectomy (RC) with pelvic node dissection. Evidence supporting the use of neoadjuvant chemotherapy in improving survival has been demonstrated in the Advance Bladder Cancer (ABC) Metanalysis 2003, 2005 [31, 32]. Nevertheless, 5 year survival was less than $50 \%$ in the metanalysis. Bladder cancer survivors following radical cystectomy can have a

\footnotetext{
*Correspondence to: Dr. Arafat Mirza, 21 Stanton Avenue, Manchester, M20 2PG, UK. Tel.: +44 07951861962; E-mail: Arafat.mirza@nhs.net.
}

significant impact on their quality of life with an ileal conduit leading to an altered body image, and genitourinary or sexual dysfunction [46].

Radiotherapy has been most commonly used with curative intent for patients considered unfit for surgery. However, in the modern era, with tri-modality management including maximal transurethral resection of bladder tumour (TURBT), radiotherapy and a radiosensitiser, outcomes are similar to those from surgery [15]. Due to the relatively better quality of life and the preservation of the patient's own bladder, bladder preservation treatment strategy is becoming an attractive alternative.

There is no randomised controlled trial evidence directly comparing surgery with bladder preservation. A UK-based multi-centre feasibility pilot study, Selective bladder Preservation Against Radical Excision (SPARE), attempted to randomise patients with complete response at cystoscopy following neoadjuvant chemotherapy, between surgery and radiotherapy [2]. However, the trial was closed due to poor accrual. This reminds us of the inherent difficulties in testing surgical versus non-surgical options for definitive treatment of cancer. Patients often find it hard 
to accept being randomised between two radically different treatment approaches. The treatment pathway becomes very complex when multiple teams are involved in delivering different components of treatment causing further difficulties in recruiting patients. Closure of this trial suggests that we might never have high quality evidence directly comparing chemoradiotherapy and radical cystectomy for MIBC.

National and international guidelines for bladder cancer management have included bladder preservation as an effective alternative treatment for MIBC. Recently published National Institute of Clinical Excellence (NICE) Guidelines in the UK recommend that patients with MIBC suitable for radical treatment should be offered a choice between radical cystectomy and radiotherapy with a radiosensitiser [3]. The guidelines recommend that a full discussion between the patient, a Urologist who performs radical cystectomy and a clinical oncologist should take place to facilitate decision making by the patient. The patient should be informed of the lack of robust evidence as to which of the two options is more effective overall and of the potential impact on sexual and bowel function as a result of the treatment. These guidelines come from an independent review of the published literature and a background where more than $50 \%$ of patients are offered chemoradiotherapy in some centres [4]. The National Comprehensive Cancer Network Guidelines include Bladder preservation with chemoradiotherapy following maximal TURBT as an alternative treatment option to radical cystectomy for MIBC [5]. The European Association of Urology Guidelines state that multimodality bladder preserving treatment for MIBC can be used as an alternative treatment in selected, well informed and compliant patients especially for whom cystectomy is not an option [6].

We will review the available evidence for bladder preservation with radiotherapy, its advantages in terms of morbidity and quality of life and the various practices of delivering radiotherapy that have been reported.

\section{EVIDENCE FOR BLADDER PRESERVATION STRATEGY SHOWING SURVIVAL SIMILAR TO RADICAL CYSTECTOMY}

Bladder preservation was initially investigated in cohort studies in the 1980s. In these studies patients underwent an initial phase of neoadjuvant radiother- apy or chemoradiotherapy followed by an assessment of response. Patients who achieved a pathological complete response were chosen for bladder preservation and underwent a further boost of radiotherapy. Patients with incomplete response underwent radical cystectomy. This strategy gave an overall survival of $59 \%$ at three years and $54 \%$ at 5 years $[7,8]$.

Based on similar protocols RTOG designed phase I/II trials testing various chemotherapy and radiotherapy regimens and adjuvant chemotherapy [9-11]. All these trials gave similar 3 year survival (61 to $83 \%$ ). Salvage cystectomy rates were 21 to $29 \%$.

Large retrospective observational cohort studies show inferior overall survival for patients undergoing radiotherapy as the definitive treatment for MIBC [13, 14]. This is likely due to confounding factors. Patients undergoing bladder radiotherapy tend to be older and have multiple comorbidities. Another cause of bias in the retrospective observational studies is discordance between clinical and pathological stage with potential understaging of patients undergoing bladder preservation. For instance, in a series publishing outcomes of clinically T2N0 stage MIBC, $73 \%$ of patients were upstaged on cystectomy to either T3, T4 or to node positive disease [12]. Appropriate statistical corrections for the above mentioned confounding factors reveal similar survival in patients undergoing bladder preservative therapy and radical cystectomy [13, 14]. Most recently, a large population-based outcome study from Canadaalsodemonstrated similar 5 yearcause specific survival (CSS) $40 \%$ in RC and 35\% in radiotherapy cases [15]. Cause specific survival may be a better indicator of outcomes from bladder preservation as patients tend to be older with multiple co-morbidities who die of causes other than bladder cancer.

Two cancer centres in the United Kingdom have published retrospective analyses and have shown similar outcomes from both the modalities of treatment. Munroe et al showed overall survival at 10 years was $21.6 \%$ for radiotherapy against $24.1 \%$ for surgery for MIBC [16]. Likewise, Kotwal et al reported overall 5 -year survival rates for primary radical radiotherapy and radical cystectomy at $34.6 \%$ and $41.3 \%$, respectively. In this study, five year cause specific survival rates (CSS) for radiotherapy and radical cystectomy group were $56.8 \%$ and $53.4 \%$, respectively. The difference was not statistically significant.

A case controlled study published this year also showed similar outcomes from surgery and chemoradiotherapy for MIBC [17]. Thirty three patients who were treated with chemoradiotherapy due to poor fitness for surgery were matched with patients 


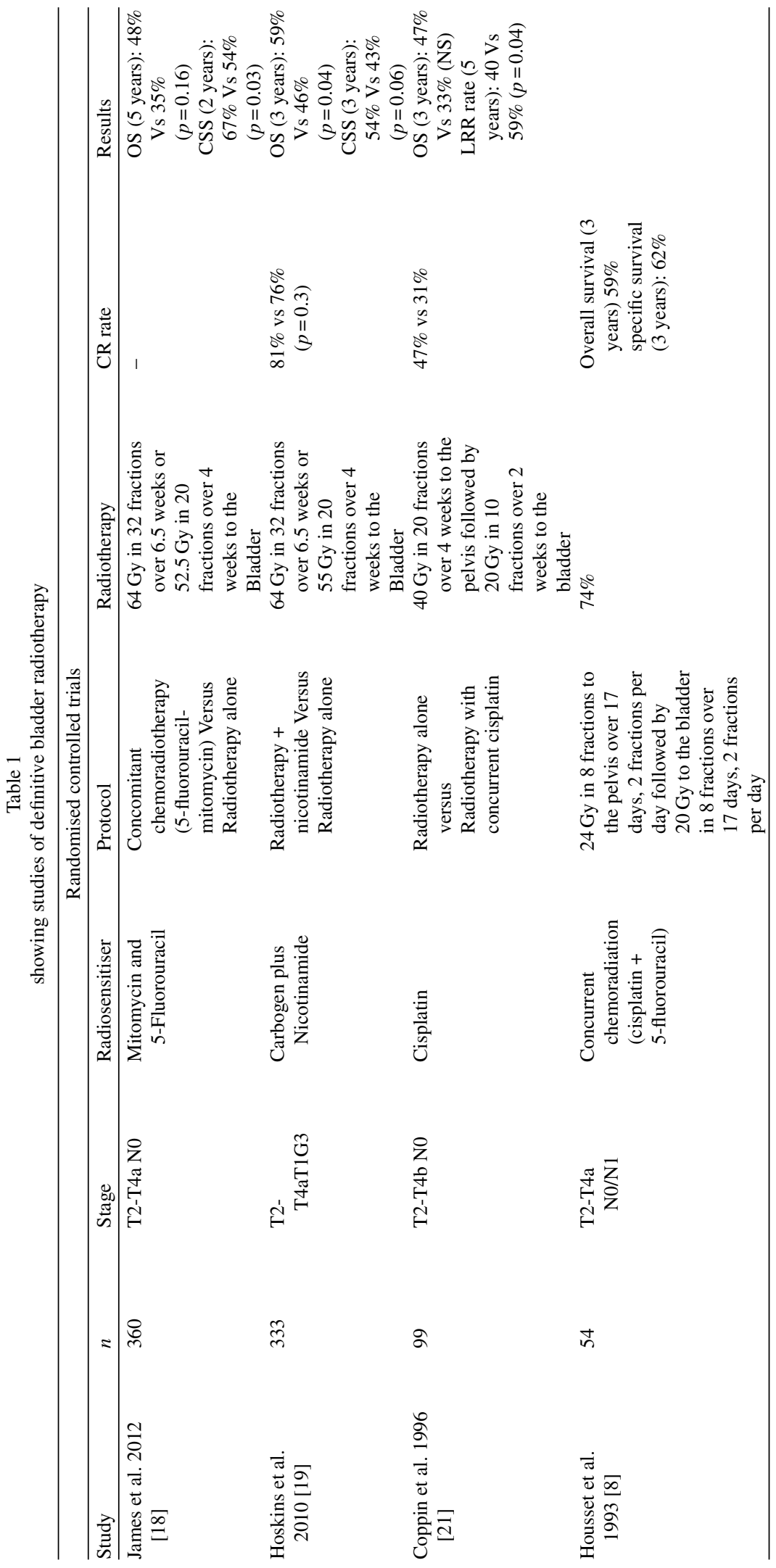




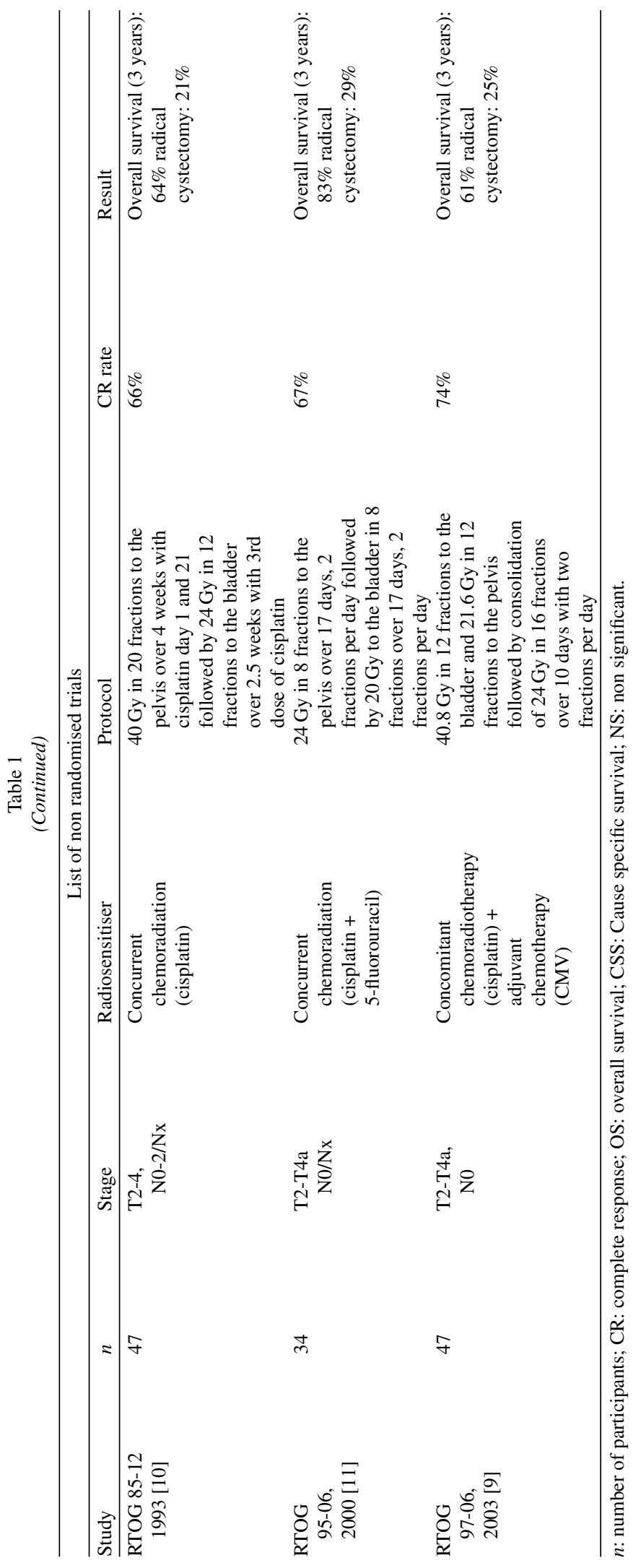


with similar age that underwent radical cystectomy in the same year. Five year disease free survival after surgery and chemoradiotherapy was $63.2 \%$ and $54 \%$ respectively. Fiver year overall survival was $54.8 \%$ and $56.6 \%$ after surgery and chemoradiotherapy respectively.

The two largest randomised controlled trials investigating the benefit of addition of radiosensitiser to radical radiotherapy as the definitive treatment for MIBC demonstrated overall survival of $48 \% 5$ year survival [BC2001 (Bladder Cancer 2001)] [18] and $59 \% 3$ year survival [BCON (Bladder Carbogen Nicotinamide)] [19]. Other randomised trials investigating inclusion of pelvic nodes in node negative patients and partial bladder radiotherapy with escalated dose also showed similar survival of 53\% and $58 \%[21,39,41]$. These trials had bladder preservation rates of 50 to $85 \%$.

These survival figures compare favourably with those of a very large surgical series [20]. Five year overall survival in this series of patients undergoing radical cystectomy depending on cancer stage was $66 \%$ although $40 \%$ of the patients in this cohort had superficial bladder cancer patients. A summary of the important randomised and non randomised studies on definitive bladder radiotherapy is listed in Table 1.

\section{RADIOSENSITISING AGENTS}

A number of agents have been shown to increase the efficacy of radiotherapy when given concomitantly with radiotherapy in MIBC. Cisplatin has been used the longest. Up until BC2001 and BCON were published, a Canadian trial [21] was the only randomised controlled phase 3 trial investigating a radiosensitising agent which had shown benefit of adding cisplatin to radiotherapy in improving local control. The trial did not have adequate power to demonstrate a survival benefit. Several case series have been published showing benefit of concomitant cisplatin with radiotherapy over radiotherapy alone [22-24].

Cisplatin is nephrotoxic drug and many bladder cancer patients do not have adequate renal function to receive cisplatin safely. $\mathrm{BC} 2001$ trial showed that fluorouracil and mitomycin-C is a suitable choice for radiosensitisation in MIBC in which hydronephrosis and impaired renal function are commonly occurring issues. With concomitant use of these drugs the 2 year locoregional disease free survival improved significantly from $54 \%$ to $67 \%$. Secondary outcome of 5 year overall survival improved from $35 \%$ to $48 \%$ but this was not statistically significant. The BCON trial showed radiotherapy along with carbogen and nicotinamide improved 3 year recurrence free survival from $43 \%$ to $54 \%$ and 3 year overall survival from $46 \%$ to $59 \%$ (both outcomes were statistically significant). Gemcitabine which has an established role in MIBC in the neoadjuvant and metastatic setting has shown benefits when given concurrently with radiotherapy in a multi-centre phase 2 trial with 50 patients [25]. Complete response rate was $88 \%, 3$ year cause specific survival was $82 \%$ and 3 year overall survival was $75 \%$ [26].

Other radiosensitising agents which have been investigated but are not part of standard treatment include Paclitaxel, intra-arterial chemotherapy and hyperthermia. Use of Paclitaxel as a concomitant drug with RT was published in a case series of patients not suitable for cisplatin chemotherapy [27]. Complete response was achieved in 24 out of 28 patients that underwent TURBT 6 weeks after completion of treatment. Intra-arterial chemotherapy with cisplatin delivered concurrently with radiotherapy has been used in some centres in Japan. In a case series of T2-3 N- MIBC complete response rates of around $80 \%$ were achieved [28]. 5 year cause specific and overall survival was $86 \%$ and $69 \%$. Hyperthermia has been considered to have a radiosensitising effect [29] and has been investigated in various malignancies including bladder. A RCT investigating radiotherapy with hyperthermia and radiotherapy alone including patients with cervical, rectal and bladder cancer showed improved outcomes especially in cervical cancer [30]. Bladder cancer patients $(n=101)$ had a CR rate of $73 \%$ with hyperthermia against $51 \%$ with radiotherapy alone but there was no improvement in local control or survival.

\section{NEOADJUVANT CHEMOTHERAPY IN BLADDER PRESERVATION STRATEGY WITH CHEMORADIOTHERAPY}

The role of neoadjuvant chemotherapy (NAC) with cisplatin based combination in MIBC has been established since publication of metanalysis in 2003 [31] and its update in 2005 [32]. Out of the 11 RCTs, 4 trials included patients with definitive radiotherapy. The largest study in the analysis was the BA06 trial [33] which was a randomised controlled trial that showed $6 \%$ absolute 10 year survival advantage with NAC. Around half of the patients underwent definitive radiotherapy in this study. Reduction in relative risk of death 
from NAC in the radiotherapy group was $20 \%$ with confidence interval of the hazard ratio just crossing 1 . Radiotherapy and cystectomy groups were not very well balanced in terms of patient characteristics. Nevertheless an interaction analysis showed that there was no evidence that NAC was any less effective when combined with either radiotherapy or cystectomy. None of the trials in the meta-analysis investigated chemoradiotherapy as concurrent chemotherapy was not an established practice at the time. Therefore, the benefit of neoadjuvant chemotherapy with concurrent chemoradiotherapy is not clearly defined.

RTOG 89-03 comparing neoadjuvant chemotherapy followed by concurrent chemoradiotherapy versus chemoradiotherapy alone was prematurely closed due to high rates of neutropenia and sepsis [34]. No significant benefit was observed with neoadjuvant chemotherapy in terms of complete response or survival. Phase II trials of neoadjuvant chemotherapy followed by chemoradiotherapy were undertaken that showed overall survival at 5 years around 50\% $[35,36]$.

The BC2001 protocol allowed neoadjuvant chemotherapy but did not mandate it. About onethird of patients received neoadjuvant chemotherapy. In a pre-planned subgroup analysis the benefit of chemoradiotherapy against radiotherapy alone in locoregional control was consistent regardless of neoadjuvant chemotherapy suggesting that neoadjuvant and concomitant chemotherapy confer separate benefits. Therefore, the benefit of neoadjuvant chemotherapy could be independent of the role of concurrent chemotherapy. However until we have more direct evidence, the role of neoadjuvant chemotherapy in patients undergoing chemoradiotherapy will remain unclear.

\section{PELVIC NODAL IRRADIATION IN BLADDER CANCER}

Patients with pelvic lymph node metastases have a worse prognosis [20]. Surgical series have shown that survival improves with increasing number of lymph nodes dissected [37]. Since definitive radiotherapy is an effective treatment for bladder cancer and dissecting pelvic nodes seems to improve outcomes, it has been suggested that including pelvic lymph nodes in the radiation field may improve local control or even survival.

In the BC2001 trial radiotherapy target was only bladder. Pelvic lymph node recurrence rate was low at
$5 \%$ in the chemoradiotherapy group. This is comparable to a large radical cystectomy series [20], where local recurrence in patients with lymph node negative disease was $6 \%$ and $13 \%$ for organ confined and extravesicular tumours, respectively. Even though the BC2001 trial did not include patients with clinical node positive disease, chances of occult metastasis in radiological node negative disease exist. For instance, in a surgical series of radical cystectomy in cT2N0 bladder urothelial cancers, occult positive lymph nodes were found in $24 \%$ of patients [38]. Unplanned inclusion of pelvic lymph nodes in the planning target volume may explain the low rate of lymph node recurrence. Secondly, use of concomitant chemotherapy may have targeted nodal micrometastatic disease.

In a randomised trial comparing pelvic nodal irradiation (45 Gy plus 20 Gy bladder boost) with bladder only irradiation ( $65 \mathrm{~Gy}$ ) rate of pelvic nodal relapse in patients with complete response was similar in both the groups at $15.8 \%$ and $17.6 \%$ [39]. Overall survival was also similar at $51 \%$ Vs $52.9 \%$. Higher rate of pelvic nodal relapse compared to BC2001 is likely to be because $50 \%$ patients were staged $\mathrm{T} 3$ and over whereas in $\mathrm{BC} 2001$ it was $15 \%$.

From the evidence so far there is no strong support for irradiation of pelvic nodes in clinically node negative bladder cancers. Future direction on this subject may be to investigate benefit of delivering higher than conventional doses to the pelvic nodes which may now be possible with advanced radiotherapy techniques.

Evidence on pelvic nodal irradiation in clinically node positive bladder cancer is sparse. None of the modern phase 3 randomised trials included node positive patients. RTOG 8802 [40] and 851210 phase 2 trials included handful of patients with node positive disease but the numbers were too small to make any meaningful conclusion.

\section{PARTIAL BLADDER IRRADIATION}

Irradiation of the entire bladder is commonly practiced due to frequent multifocality of the tumour. Partial bladder irradiation has been investigated in order to reduce late toxicity and enable escalating radiation dose to the tumour itself. Two randomised trials can be mentioned here.

Cowan et al. [41] randomised patients into one of three arms: the control arm with radiotherapy alone to the whole bladder $(52.5 \mathrm{~Gy}$ in 20 fractions over 4 weeks), and 2 study arms of partial bladder irradiation (bladder tumour with $1.5 \mathrm{~cm}$ margin) for the 
entire course of treatment. In the first study arm there was dose escalation to $57.5 \mathrm{~Gy}$ in 20 fractions over 4 weeks. The second study arm had dose escalation and acceleration at $55 \mathrm{~Gy}$ in 16 fractions over 3 weeks and one day. The trial did not show any improvement in local control rates with partial bladder dose escalated radiotherapy.

The BC2001 trial [42] sub-study investigated partial bladder radiotherapy. In the control arm patients received $64 \mathrm{~Gy}$ in 32 fractions or $55 \mathrm{~Gy}$ in 20 fractions to the entire bladder. In contrast to Cowan et al, in this trial the study arm patients received standard dose to the tumour with a margin and $80 \%$ reduced dose to the rest of the bladder. Non inferiority of partial bladder irradiation could not be established as the study had inadequate power from early closure due to slow recruitment. Late radiation toxicity was similar in whole bladder and partial bladder irradiation groups with RTOG Grade 3/4 GU toxicity at 2 years $2.4 \%$ and 5.4 respectively and GI toxicity $0 \%$ and $1 \%$ respectively.

\section{ADVANTAGES OF BLADDER PRESERVATION IN TERMS OF QUALITY OF LIFE}

Radical cystectomy has significant morbidity associated with it [43]. Major post operative complications rate within 30 days including small bowel obstruction, sepsis and cardiorespiratory complications can up to $25 \%$. Thirty day mortality is 2 to $3 \%$. Long term morbidity from radical cystectomy results mainly from urinary (recurrent UTIs, renal stones, uretero-ileal stricture, renal failure), gastrointestinal (rectal incontinence, intestinal obstruction) and sexual dysfunction [44]. In another study late toxicity (defined as more than 3 months after cystectomy) was recorded in $46 \%$ of patients [45]. Toxicities included ileus, intestinal anastomosis leakage, wound problems, stoma problems, ureter/ureter anastomosis problems, urethral anastomosis problems, leakage pouch and pelvic abscess requiring drainage.

Adverse effects from radiotherapy are also related to urinary, bowel and sexual function. Acute genitourinary (GU) and gastrointestinal (GI) toxicity of Grade 3 or 4 occurs in 30-40\% of patients. However, for most patients, these symptoms are transient with complete resolution within a few months resulting in Radiation Therapy Oncology Group (RTOG) late toxicity of G3/4 at 1 year of $3.3 \%$ for GU and $1.3 \%$ for GI symptoms [18].
Radical cystectomy does have a significant impact on quality of life despite major advancements in surgical techniques. Quality of life was found to be impaired with a radical cystecomy due to the presence of a stoma and reduced sexual activity in patients [46]. Long term results of bladder function and quality of life in patients who received bladder preservation after 6.3 years of follow up showed $75 \%$ of patients maintained normal bladder function and 59\% maintained satisfactory sexual function [47]. In a case control study which reported quality of life, $74 \%$ of the patients in the radiotherapy group had little or no distress from urinary symptoms [48]. Moderate to severe distress from gastrointestinal symptoms was reported by $32 \%$ of radiotherapy patients and $24 \%$ of cystectomy patients. $38 \%$ had sexual intercourse in the previous month in the radiotherapy group compared with $13 \%$ in cystectomy group. Interestingly, $46 \%$ of the patients reported that they were willing to accept some reduction in survival to remain symptom free. In another cross-sectional multi-institutional study of 173 patients which compared long-term QOL in MIBC patients treated with bladder preservation and radical cystectomy, bladder preservation was associated with better general quality of life and bowel function compared to cystectomy while urinary quality of life was equivalent between the groups [49].

\section{PATIENT SELECTION CRITERIA}

In most of the retrospective series, patients who had bladder preservation strategies were either those who were medically unfit for radical cystectomy or had unresectable tumour or those that actively sought bladder preservation against the standard of care recommendation. There is currently no consensus on criteria for identifying the best candidates for bladder preservation [50-52].

Some bladder preservation protocols mandate macroscopic complete trans-urethral resection of bladder tumour (TURBT) [AFU 2013, NCCN 2014]. Complete resection of bladder tumour has been shown to improve survival and reduce salvage cystectomy rate $[53,54]$. However, a tumour that was amenable to complete resection may represent a lower $\mathrm{T}$ stage in itself. This suggests that a complete TURBT may be a prognostic rather than predictive factor for response to treatment. It should be noted that large randomised trials BC2001 and BCON included patients with incomplete tumour resection 
(27\% and $63 \%$ respectively) with clinical outcomes similar to those of surgery.

Hydronephrosis can be present in 15-20\% of patients with bladder cancer at diagnosis $[55,56]$. Presence of hydronephoris was shown to be associated with poorer disease specific survival and overall survival in a univariate analysis but not on multivariate analysis [54]. Some authors deem hydronephrosis as a relative contraindication for definitive bladder radiotherapy $[57,58]$. The $\mathrm{BC} 2001$ and $\mathrm{BCON}$ trials did not have hydronephrosis in the exclusion criteria. However there were only 3 out of the over 300 patients in the trial who had hydronephrosis in the BCON trial. BC2001 did not report on the number of patients with hydronephrosis. In a phase II trial inves- tigating concurrent gemcitabine with radiotherapy in bladder cancer, which had $88 \%$ complete response rate and $82 \% 3$ year cancer specific survival, 5 out of the 46 patients had hydronephrosis [25].

Hydronephrosis has been shown to be an independent prognostic factor for recurrence free survival even in surgical series [59]. Patients with hydronephrosis tend to have more advanced disease with higher risk of extra vesicular disease and pelvic nodal involvement. Therefore hydronephrosis is probably not a predictive factor for poor outcomes from definitive bladder radiotherapy but rather a prognostic factor for bladder cancer. A retrospective series showed an increased risk of persistent tumour in patients with ureteric obstruction

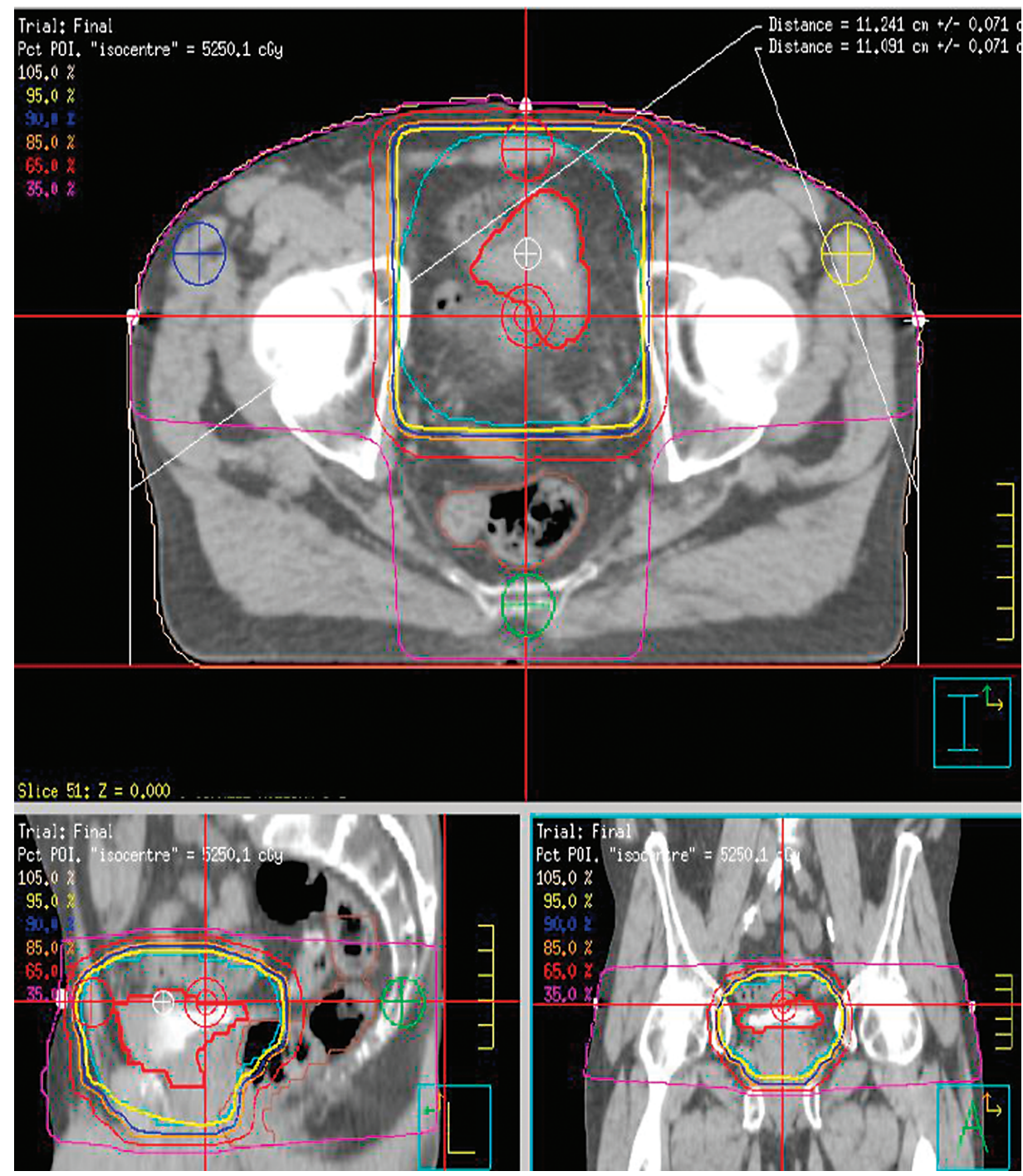

Fig. 1. A typical 3 dimensional conformal radiotherapy plan for treating bladder cancer. 
following treatment with radiotherapy $(51 \% \mathrm{Vs}$ $25 \%$ ) [60]. This series was of patients treated prior to 1990 and the radiotherapy dose delivered was variable. Radiotherapy techniques are much more advanced now. Computer tomographic radiotherapy planning and more recently image guided radiotherapy have improved the accuracy of treatment. Figure 1 shows a typical Bladder radiotherapy plan. Addition of radiosensitising agents has made radiotherapy more effective. Complete response rates can be up to $90 \%$ with chemoradiotherapy $[25,39]$. Mitomycin and 5-Flurouracil, Gemcitabine, Carbogen and Nicotinamide have proven efficacy as radiosensitising agents and are safer in renal impairment compared to cisplatin. Therefore we propose that hydronephrosis should not be considered a contraindication for bladder preservative treatment.

Nomograms have been developed to identify patients who might benefit the most from bladder preservation strategies [57]. In this nomogram, hydronephrosis scores against undertaking bladder preservation due to risk of inferior complete response (CR) rate and disease specific survival rate. This nomogram is based on a retrospective series of patients who were otherwise medically fit to undergo radical cystectomy but preferred to preserve their bladder. Patients underwent cystoscopic assessment for response after first phase of 40 Gy in 2 Gy per fraction of radiation. This dose is probably inadequate to achieve a CR as in recent randomised phase III trials with radiosensitisation, patients received an equivalent dose of $64 \mathrm{~Gy}$ in $2 \mathrm{~Gy}$ per fraction with the first assessment of response at 3 months after completing treatment.

Among other factors that are often used to identify suitable patients for bladder preservation are multifocality of tumour and presence of carcinoma in situ (CIS) with both these shown to increase risk of local recurrence [61, 62]. In a series, 11 out of 19 patients who had CIS or Grade 2 dysplasia at initial presentation developed new bladder tumour recurrence following a complete primary tumour response after radical radiotherapy [63]. CIS associated with the original MIBC is a strong predictor of subsequent recurrence of superficial bladder tumours which can be managed conservatively with little impact on survival [64]. Thus presence of CIS should not necessarily be considered an absolute contraindication for definitive bladder radiotherapy.

Careful assessment of baseline bladder function should be undertaken prior to selecting patients for bladder preservation strategies. Since the main advan- tage in preserving the bladder is focused on quality of life, pre-existent distressful bladder symptoms, which may indeed get worse following radiotherapy, may make bladder preservation futile in some instances. Frank discussion with patients is however very important as patients might still wish to preserve their bladder and persevere with bladder symptoms.

Urothelial cell cancers can occur inside bladder diverticulae. These tumours present some challenges including difficulty in visualisation and access due to narrow neck of the diverticulum. Absence of muscle layer within the diverticular wall makes it difficult to resect the tumour safely and to give a pathological stage to tumour. Patients with intradiverticular urothelial cancers are generally considered poor candidates for bladder preservative treatment strategies. The radiation target required to cover all the diverticulae may become quite large which may result in increased normal tissue toxicity. Careful visualisation of the bladder mucosa with flexible cystoscopy is integral to an effective surveillance following chemoradiotherapy for bladder cancer. Bladder diverticulae make cystoscopic surveillance unreliable. One explanation for development of bladder diverticulae is excessive pressure inside the bladder from to outflow obstruction [65]. These patients may have a poor baseline bladder function thus making bladder preservation strategies futile.

Lastly, patients who have had previous radiotherapy to the pelvis for rectal, anal, prostate, cervical or endometrial cancers will not be suitable for bladder preservation with radiotherapy.

\section{BIOMARKERS FOR PREDICTING RADIOTHERAPY RESPONSE}

Controversy exists as to the selection of patients for bladder preservation, with a number of prognostic criteria such as hydronephrosis, presence of CIS and a complete TURBT being used to determine radical treatment. There has been recent interest in studying molecular markers that can predict response to a particular cancer treatment. For a marker to be considered predictive, its presence or absence should demonstrate a clear difference in the outcomes of only the treatment in question. If other treatment modalities also show variable outcomes then the marker is likely to be prognostic rather than predictive. Furthermore, these markers need to be validated by more than one study across different cohorts before it can be put forward for clinical use. At least two such 
markers studied recently are worth a mention here in relation to bladder preservation.

The MRE11 gene encodes a nuclear protein involved in DNA double-strand break repair. Bladder cancer patients with high expression of this protein respond better to radical radiotherapy than those with low expression $[66,67]$. This difference has not been correlated with better outcomes in cystectomy cohort. Presence of necrosis in TURBT material has been shown to predict a greater benefit in terms of overall survival by using hypoxia modifiers in the BCON study [68]. Necrosis was shown to be a negative prognostic factor in a retrospective observational study of bladder cancer patients undergoing cystectomy [69]. However in another retrospective series of cystectomy patients necrosis was shown to be prognostic on univariate but not on multivariate analysis [70].

\section{FOLLOW UP}

Rate of recurrence within the bladder after bladder preservation treatment with chemoradiotherapy can be 20 to $25 \%[18,19]$. Most of these occur in the first 2 to 3 years. Relapses within the bladder can be potentially salvaged with appropriate treatment. Muscle invasive recurrences can be treated with radical cystectomy with acceptable albeit slightly higher complication rate [71]. Survival rates of up to $50 \%$ can be achieved in patients undergoing salvage cystecomy [23]. Superficial bladder recurrences can be managed with TURBT and intravesical therapies [64]. Therefore a robust cystoscopy surveillance programme should be in place to detect early recurrences. There is no evidence for an optimal follow up schedule. UK NICE guidelines recommend surveillance cystoscopy every 3 months for 2 years, every 6 months for the next 2 years and then yearly thereafter.

\section{CONCLUSION}

Bladder preservative strategy is now considered an effective alternative for treatment of MIBC and finds its place in major national and international guidelines. Radical radiotherapy with a radiosensitiser should be considered and offered to all patients with MIBC not just those who are considered medically unfit to undergo radical cystectomy or those who by themselves demand bladder preservation.

\section{CONFLICT OF INTEREST}

The authors have no conflict of interest to report.

\section{REFERENCES}

[1] Cancer Research UK statistics.

[2] Huddart RA, Hall E, Lewis R, Birtle A. SPARE Trial Management Group. Life and death of spare (selective bladder preservation against radical excision): Reflections on why the spare trial closed. BJU Int 2010;106(6):753-5.

[3] https://www.nice.org.uk/guidance/ng2

[4] Kotwal S, Choudhury A, Johnston C, Paul AB, Whelan P, Kiltie AE. Similar treatment outcomes for radical cystectomy and radical radiotherapy in invasive bladder cancer treated at a United Kingdom specialist treatment center. Int J Radiat Oncol Biol Phys 2008;70(2):456-63.

[5] NCCN Guidelines Version 2.2015 Bladder Cancer. http:// www.nccn.org/professionals/physician_gls/pdf/bladder.pdf

[6] Guidelines on Muscle-invasive and Metastatic Bladder Cancer European Association of Urology 2015. http:// uroweb.org/wp-content/uploads/EAU-Guidelines-Muscleinvasive-and-Metastatic-Bladder-Cancer-2015-v1.pdf

[7] Shipley WU, Kaufman DS, Zehr E, Heney NM, Lane SC, Thakral HK, et al. Selective bladder preservation by combined modality protocol treatment: Long-term outcomes of 190 patients with invasive bladder cancer Urology 2002;60:62-7.

[8] Housset M, Maulard C, Chretien Y, Dufour B, Delanian $\mathrm{S}$, Huart J, et al. Combined radiation and chemotherapy for invasive transitional-cell carcinoma of the bladder: A prospective study J Clin Oncol 1993;11:2150-7.

[9] Hagan MP, Winter KA, Kaufman DS, Wajsman Z, Zietman AL, Heney NM, et al. RTOG 97-06: Initial report of a phase I-II trial of selective bladder conservation using TURBT, twice-daily accelerated irradiation sensitized with cisplatin, and adjuvant MCV combination chemotherapy Int J Radiat Oncol Biol Phys 2003;57:665-72.

[10] Tester W, Porter A, Asbell S, Coughlin C, Heaney J, Krall J, et al. Combined modality program with possible organ preservation for invasive bladder carcinoma: Results of RTOG protocol 85-12 Int J Radiat Oncol Biol Phys 1993;25:783-90.

[11] Kaufman DS, Winter KA, Shipley WU, Heney NM, Chetner MP, Souhami L, et al. The initial results in muscleinvading bladder cancer of RTOG 95-06: Phase I/II trial of transurethral surgery plus radiation therapy with concurrent cisplatin and 5-fluorouracil followed by selective bladder preservation or cystectomy depending on the initial response Oncologist 2000;5:471-6.

[12] Canter D, Long C, Kutikov A, Plimack E, Saad I, Oblaczynski M, Zhu F, Viterbo R, Chen DY, Uzzo RG, Greenberg RE, Boorjian SA. Clinicopathological outcomes after radical cystectomy for clinical T2 urothelial carcinoma: Further evidence to support the use of neoadjuvant chemotherapy. BJU Int 2011;107(1):58-62.

[13] Kozak KR, Hamidi M, Manning M, Moody JS. Bladder preservation for localized muscle-invasive bladder cancer: The survival impact of local utilization rates of definitive radiotherapy. Int J Radiat Oncol Biol Phys 2012;83(2):e197204. doi: 10.1016/j.ijrobp.2011.12.038. Epub 2012 Mar 6.

[14] Bekelman JE, Handorf EA, Guzzo T, Evan Pollack C, Christodouleas J, Resnick MJ, Swisher-McClure S, 
Vaughn D, Ten Have T, Polsky D, Mitra N. Radical cystectomy versus bladder-preserving therapy for muscleinvasive urothelial carcinoma: Examining confounding and misclassification biasin cancer observational comparative effectiveness research. Value Health 2013;16(4):610-8.

[15] Booth CM, Siemens DR, Li G, Peng Y, Kong W, Berman DM, Mackillop WJ. Curative therapy for bladder cancer in routine clinical practice: A population-based outcomes study. Clin Oncol (R Coll Radiol) 2014;26(8):506-14.

[16] Munro NP, Sundaram SK, Weston PM, Fairley L, Harrison SC, Forman D, Chahal R. A 10-year retrospective review of a nonrandomized cohort of 458 patients undergoing radical radiotherapy or cystectomy in Yorkshire, UK. Int J Radiat Oncol Biol Phys 2010;77(1):119-24.

[17] Gofrit ON, Nof R, Meirovitz A, Pode D, Frank S, Katz R, Shapiro A, Landau EH, Hidas G, Yutkin V, Duvdevani M, Wygoda M. Radical cystectomy vs. Chemoradiation in T24aNOM0 bladder cancer: A case-control study. Urol Oncol 2015;33(1):19.

[18] James ND, Hussain SA, Hall E, Jenkins P, Tremlett J, Rawlings C, Crundwell M,Sizer B, Sreenivasan T, Hendron C, Lewis R, Waters R, Huddart RA. BC2001 Investigators. Radiotherapy with or without chemotherapy in muscle-invasive bladder cancer. $\mathrm{N}$ Engl $\mathrm{J}$ Med 2012;366(16):1477-88.

[19] Hoskin PJ, Rojas AM, Bentzen SM, Saunders MI. Radiotherapy with concurrent carbogen and nicotinamide in bladder carcinoma. J Clin Oncol 2010;28(33):4912-8.

[20] Stein JP, Lieskovsky G, Cote R, Groshen S, Feng AC, Boyd S, Skinner E, Bochner B, Thangathurai D, Mikhail M, Raghavan D, Skinner DG. Radical cystectomy in the treatment of invasive bladder cancer: Long-term results in 1,054 patients. J Clin Oncol 2001;19(3):666-75.

[21] Coppin CM, Gospodarowicz MK, James K, Tannock IF, Zee B, Carson J, Pater J, Sullivan LD. Improved local control of invasive bladder cancer by concurrent cisplatin and preoperative or definitive radiation. The National Cancer Institute of Canada Clinical Trials Group. J Clin Oncol 1996;14(11):2901-7.

[22] Sauer R, Dunst J, Altendorf-Hofmann A, Fischer H, Bornhof C, Schrott KM. Radiotherapy with and without cisplatin in bladder cancer. Int J Radiat Oncol Biol Phys 1990;19(3):687-91.

[23] Rödel C, Grabenbauer GG, Kühn R, Papadopoulos T, Dunst J, Meyer M, Schrott KM, Sauer R. Combinedmodality treatment and selective organ preservation in invasive bladder cancer: Long-term results. J Clin Oncol 2002;20(14):3061-71.

[24] Hussain MH, Glass TR, Forman J, Sakr W, Smith DC, AlSarraf M, Jones J, Balcerzak SP, Crawford ED, Grossman HB. Combination cisplatin, 5-fluorouracil and radiation therapy for locally advanced unresectable or medically unfit bladder cancer cases: A Southwest Oncology Group Study. J Urol 2001;165(1):56-60.

[25] Choudhury A, Swindell R, Logue JP, Elliott PA, Livsey JE, Wise M, Symonds P, Wylie JP, Ramani V, Sangar V, Lyons J, Bottomley I, McCaul D, Clarke NW, Kiltie AE, Cowan RA. Phase II study of conformal hypofractionated radiotherapy with concurrent gemcitabine in muscle-invasive bladder cancer. J Clin Oncol 2011;29(6):733-8.

[26] Oh KS, Soto DE, Smith DC, Montie JE, Lee CT, Sandler HM. Combined-modality therapy with gemcitabine and radiation therapy as a bladder preservation strategy: Longterm results of a phase I trial. Int J Radiat Oncol Biol Phys 2009;74(2):511-7.
[27] Müller AC, Diestelhorst A, Kuhnt T, Kühn R, Fornara P, Scholz HJ, Dunst J, Zietman AL. Organ-sparing treatment of advanced bladder cancer: Paclitaxel as a radiosensitizer. Strahlenther Onkol 2007;183(4):177-83.

[28] Matsumoto Y, Samma S, Fukui S, Nakai Y, Kagebayashi Y, Torimoto K. External beam radiation plus concurrent intraarterial chemotherapy with low dose cisplatin for muscle invasive bladder cancer. Indian J Urol 2015;31(1):52-6.

[29] Kampinga HH, Dikomey E. Hyperthermic radiosensitization: Mode of action and clinical relevance. Int J Radiat Biol 2001;77(4):399-408.

[30] van der Zee J, González González D, van Rhoon GC, van Dijk JD, van Putten WL, Hart AA. Comparison of radiotherapy alone with radiotherapy plus hyperthermia in locally advanced pelvic tumours: A prospective, randomised, multicentre trial. Dutch Deep Hyperthermia Group. Lancet 2000;355(9210):1119-25.

[31] Advanced Bladder Cancer Meta-analysis Collaboration. Neoadjuvant chemotherapy in invasive bladder cancer: A systematic review and meta-analysis. Lancet 2003;361(9373):1927-34.

[32] Advanced Bladder Cancer (ABC) Meta-analysis Collaboration. Neoadjuvant chemotherapy in invasive bladder cancer: Update of a systematic review and meta-analysis of individual patient data advanced bladder cancer (ABC) meta-analysis collaboration. Eur Urol 2005;48(2): 202-5.

[33] International Collaboration of Trialists; Medical Research Council Advanced Bladder Cancer Working Party (now the National Cancer Research Institute Bladder Cancer Clinical Studies Group); European Organisation for Research and Treatment of Cancer Genito-Urinary Tract Cancer Group; Australian Bladder Cancer Study Group; National Cancer Institute of Canada Clinical Trials Group; Finnbladder;Norwegian Bladder Cancer Study Group; Club Urologico Espanol de Tratamiento Oncologico Group, Griffiths G, Hall R, Sylvester R, Raghavan D, Parmar MK. International phase III trial assessing neoadjuvant cisplatin, methotrexate, and vinblastine chemotherapy for muscleinvasive bladder cancer: Long-term results of the BA06 30894 trial. J Clin Oncol 2011;29(16):2171-7.

[34] Shipley WU, Winter KA, Kaufman DS, Lee WR, Heney NM, Tester WR, Donnelly BJ, Venner PM, Perez CA, Murray KJ, Doggett RS, True LD. Phase III trial of neoadjuvant chemotherapy in patients with invasive bladder cancer treated with selective bladder preservation by combined radiation therapy and chemotherapy: Initial results of Radiation Therapy Oncology Group 89-03. J Clin Oncol 1998;16(11):3576-83.

[35] Tester W, Caplan R, Heaney J, Venner P, Whittington R, Byhardt R, et al. Neoadjuvant combined modality program with selective organ preservation for invasive bladder cancer: Results of Radiation Therapy Oncology Group phase II trial 88-02 J Clin Oncol 1996;14:119-26.

[36] Fellin G, Graffer U, Bolner A, Ambrosini G, Caffo O, Luciani L. Combined chemotherapy and radiation with selective organ preservation for muscle-invasive bladder carcinoma. A single-institution phase II study. Br J Urol 1997;80(1):44-9.

[37] Wright JL, Lin DW, Porter MP. The association between extent of lymphadenectomy and survival among patients with lymph node metastases undergoing radical cystectomy. Cancer 2008;112(11):2401-8.

[38] Pietzak EJ, Sterling ME, Smith ZL, Malkowicz SB, Guzzo TJ. Outcomes of radical cystectomy in potential candi- 
dates for bladder preservation therapy. Urology 2015;85(4): 869-75.

[39] Tunio MA, Hashmi A, Qayyum A, Mohsin R, Zaeem A. Whole-pelvis or bladder-only chemoradiation for lymph node-negative invasive bladder cancer: Single-institution experience Int J Radiat Oncol Biol Phys 2012;82: 457-462.

[40] Tester W, Caplan R, Heaney J, Venner P, Whittington R, Byhardt R, True L, Shipley W. Neoadjuvant combined modality program with selective organ preservation for invasive bladder cancer: Results of Radiation Therapy Oncology Group phase II trial 8802. J Clin Oncol 1996;14(1):119-26.

[41] Cowan RA, McBain CA, Ryder WD, Wylie JP, Logue JP, Turner SL, Van der Voet J, Collins CD, Khoo VS, Read GR. Radiotherapy for muscle-invasive carcinoma of the bladder: Results of a randomized trial comparing conventional whole bladder with dose-escalated partial bladder radiotherapy. Int J Radiat Oncol Biol Phys 2004;59(1):197-207.

[42] Huddart RA, Hall E, Hussain SA, Jenkins P, Rawlings C, Tremlett J, Crundwell M, Adab FA, Sheehan D, Syndikus I, Hendron C, Lewis R, Waters R, James ND. Randomized noninferiority trial of reduced high-dose volume versus standard volume radiation therapy for muscle-invasive bladder cancer: Results of the BC2001 trial (CRUK/01/004). Int J Radiat Oncol Biol Phys 2013;87(2):261-9. doi: 10.1016/j.ijrobp.2013.06.2044. Erratum in: Int J Radiat Oncol Biol Phys 2013;87(5):860.

[43] Manoharan M, Ayyathurai R, Soloway MS. Radical cystectomy for urothelial carcinoma of the bladder: An analysis of perioperative and survival outcome. BJU Int 2009;104(9): 1227-32.

[44] Chahal R, Sundaram SK, Iddenden R, Forman DF, Weston PM, Harrison SC. A study of the morbidity, mortality and long-term survival following radical cystectomy and radical radiotherapy in the treatment of invasive bladder cancer in Yorkshire. Eur Urol 2003;43(3):246-57.

[45] van der Steen-Banasik E, Ploeg M, Witjes JA, van Rey FS, Idema JG, Heijbroek RP, Karthaus HF, Reinders JG, Viddeleer A, Visser AG. Brachytherapy versus cystectomy in solitary bladder cancer: A case control, multicentre, East-Netherlands study. Radiother Oncol 2009;93(2): 352-7.

[46] Caffo O, Fellin G, Graffer U, Luciani L. Assessment of quality of life after cystectomy or conservative therapy for patients with infiltrating bladder carcinoma. A survey by a self-administered questionnaire. Cancer 1996;78(5):108997. Erratum in: Cancer 1996;76(9):2037.

[47] Zietman AL, Sacco D, Skowronski U, Gomery P, Kaufman DS, Clark JA, Talcott JA, Shipley WU. Organ conservation in invasive bladder cancer by transurethral resection, chemotherapy and radiation: Results of a urodynamic and quality of life study on long-term survivors. J Urol 2003;170(5):1772-6.

[48] Henningsohn L, Wijkström H, Dickman PW, Bergmark K, Steineck G. Distressful symptoms after radical radiotherapy for urinary bladder cancer. Radiother Oncol 2002;62(2):215-25.

[49] Kimberley S, Mak, et al. Quality of life in long-term survivors of muscle-invasive bladder cancer. J Clin Oncol 2015;33(suppl 7; abstr 319).

[50] Gakis G, Efstathiou J, Lerner SP, Cookson MS, Keegan KA, Guru KA, et al. ICUD-EAU International Consultation on Bladder Cancer 2012: Radical cystectomy and bladder preservation for muscle-invasive urothelial carcinoma of the bladder Eur Urol 2013;63:45-57.
[51] Hindson BR, Turner SL, Millar JL, Foroudi F, Gogna NK, Skala M, et al. 2011 consensus guidelines for curative radiotherapy for urothelial carcinoma of the bladder J Med Imaging Radiat Oncol 2012;56:18-30.

[52] Clark PE, Spiess PE, Agarwal N, Eisenberger MA, Greenberg RE, Herr HW, et al. NCCN Guidelines: Bladder Cancer (Version 2.2014) National Comprehensive Cancer Network, Fort Washington, PA (2014) http://www.ncen.org

[53] Rödel C, Grabenbauer GG, Kühn R, Papadopoulos T, Dunst J, Meyer M, Schrott KM, Sauer R. Combinedmodality treatment and selective organ preservation in invasive bladder cancer: Long-term results. J Clin Oncol 2002;20(14):3061-71.

[54] Efstathiou JA, Spiegel DY, Shipley WU, Heney NM, Kaufman DS, Niemierko A, Coen JJ, Skowronski RY, Paly JJ, McGovern FJ, Zietman AL. Long-term outcomes of selective bladder preservation by combined-modality therapy for invasive bladder cancer: The MGH experience. Eur Urol 2012;61(4):705-11.

[55] Bartsch GC, Kuefer R, Gschwend JE, de Petriconi R, Hautmann RE, Volkmer BG. Hydronephrosis as a prognostic marker in bladder cancer in a cystectomy-only series. Eur Urol 2007;51(3):690-7; discussion 697-8. Epub $2006 \mathrm{Jul}$ 28.

[56] Haleblian GE, Skinner EC, Dickinson MG, Lieskovsky G, Boyd SD, Skinner DG. Hydronephrosis as a prognostic indicator in bladder cancer patients. J Urol 1998;160(6 Pt 1):2011-4

[57] Coen JJ, Paly JJ, Niemierko A, Kaufman DS, Heney NM, Spiegel DY, Efstathiou JA, Zietman AL, Shipley WU. Nomograms predicting response to therapy and outcomes after bladder-preserving trimodality therapy for muscleinvasive bladder cancer. Int $\mathrm{J}$ Radiat Oncol Biol Phys 2013;86(2):311-6.

[58] Smith ZL, Christodouleas JP, Keefe SM, Malkowicz $\mathrm{SB}$, Guzzo TJ. Bladder preservation in the treatment of muscle-invasive bladder cancer (MIBC): A review of the literature and a practical approach to therapy. BJU Int 2013;112(1):13-25.

[59] Bartsch GC, Kuefer R, Gschwend JE, de Petriconi R, Hautmann RE, Volkmer BG. Hydronephrosis as a prognostic marker in bladder cancer in a cystectomy-only series. Eur Urol 2007;51(3):690-7; discussion 697-8. Epub 2006 Jul 28.

[60] Mameghan H, Fisher R, Mameghan J, Brook S. Analysis of failure following definitive radiotherapy for invasive transitional cell carcinoma of the bladder. Int J Radiat Oncol Biol Phys 1995;31(2):247-54.

[61] Gospodarowicz MK, Hawkins NV, Rawlings GA, Connolly JG, Jewett MA, Thomas GM, Herman JG, Garrett PG, Chua $\mathrm{T}$, Duncan W, et al. Radical radiotherapy for muscleinvasive transitional cell carcinoma of the bladder: Failure analysis. J Urol 1989;142(6):1448-53.

[62] Moonen L, vd Voet H, de Nijs R, Hart AA, Horenblas S, Bartelink H. Muscle-invasive bladder cancer treated with external beam radiotherapy: Pretreatment prognostic factors and the predictive value of cystoscopic re-evaluation during treatment. Radiother Oncol 1998;49(2):149-55.

[63] Wolf H, Olsen PR, Højgaard K. Urothelial dysplasia concomitant with bladder tumours: A determinant for future new occurrences in patients treated by full-course radiotherapy. Lancet 1985;1(8436):1005-8.

[64] Zietman AL, Grocela J, Zehr E, Kaufman DS, Young RH, Althausen AF, Heney NM, Shipley WU. Selective bladder conservation using transurethral resection, chemotherapy, 
and radiation: Management and consequences of Ta, T1, and Tis recurrence within the retained bladder. Urology 2001;58(3):380-5.

[65] Baniel J, Vishna T. Primary transitional cell carcinoma in vesical diverticula. Urology 1997;50(5):697-9. PubMed PMID: 9372877.

[66] Expression of TIP60 (tat-interactive protein) and MRE11 (meiotic recombination 11 homolog) predict treatmentspecific outcome of localised invasive bladder cancer. Laurberg JR, Brems-Eskildsen AS, Nordentoft I, Fristrup N, Schepeler T, Ulhøi BP, Agerbaek M, Hartmann A, Bertz S, Wittlinger M, Fietkau R, Rödel C, Borre M, Jensen JB, Orntoft T, Dyrskjøt L. BJU Int 2012;110(11 Pt C): E1228-36.

[67] Choudhury A, Nelson LD, Teo MTW, Chilka S, Bhattarai S, Johnston CF, et al. MRE11 expression is predictive of cause-specific survival following radical radiotherapy for muscle invasive bladder cancer. Cancer Research 2010;70(18):7017-26.

[68] Eustace A, Irlam JJ, Taylor J, Denley H, Agrawal S, Choudhury A, Ryder D, Ord JJ, Harris AL, Rojas AM,
Hoskin PJ, West CM. Necrosis predicts benefit from hypoxia-modifying therapy in patients with high risk bladder cancer enrolled in a phase III randomised trial. Radiother Oncol 2013;108(1):40-7. doi: 10.1016/j.radonc. 2013.05.017. Epub 2013 Jun 14.

[69] Ord JJ, Agrawal S, Thamboo TP, Roberts I, Campo L, Turley H, Han C, Fawcett DW, Kulkarni RP, Cranston D, Harris AL. An investigation into the prognostic significance of necrosis and hypoxia in high grade and invasive bladder cancer. J Urol 2007;178(2):677-82.

[70] Kucuk U, Pala EE, Cakır E, et al. Clinical, demographic and histopathological prognostic factors for urothelial carcinoma of the bladder. Central European Journal of Urology 2015;68(1):30-36. doi:10.5173/ceju.2015.01.465

[71] Eswara JR, Efstathiou JA, Heney NM, Paly J, Kaufman DS, McDougal WS, McGovern F, Shipley WU. Complications and long-term results of salvage cystectomy after failed bladder sparing therapy for muscle invasive bladder cancer. J Urol 2012;187(2):463-8. doi: 10.1016/j.juro.2011.09.159. Epub 2011 Dec 15. 